\title{
OPAH a model for optimal design of multipurpose small hydropower plants
}

\author{
J.P.P.G. Lopes de Almeida ${ }^{\mathrm{a}, *}$, A.G. Henri Lejeune ${ }^{\mathrm{b}}$, J.A.A. Sá Marques ${ }^{\mathrm{a}}$, M. Conceição Cunha ${ }^{\mathrm{a}}$ \\ ${ }^{\text {a }}$ Professor at the Departamento de Engenharia Civil da Universidade de Coimbra, Portugal \\ ${ }^{\mathrm{b}}$ Full Professor at the Institut du Génie Civil de la Université de Liège, Belgium
}

Received 23 January 2004; received in revised form 23 January 2004; accepted 20 June 2005

Available online 15 August 2005

\begin{abstract}
The investment in small hydropower plants requires the analysis of hydrological, technical, operational, budgetary, economical and financial aspects. The analysis of each possible configuration demands the joint action of several technicians, consuming substantial time and money. During initial design of the project, simplified procedures are usually adopted which may compromise the quality of the base configuration.

In this paper we will present a global overview of the OPAH model, which was developed to surpass these limitations. This global model performs the optimization of project configuration. This model uses non-linear programming optimization to analyze the multipurpose operation of the hydropower plant. It uses a numeric simulation model of unsteady flow under pressure to analyze the hydraulic circuit. It uses an economical and financial simulation model that takes in to account the project risk associated to hydrologic and market variability, the financial capacity of the investor and the fiscal aspects.
\end{abstract}

(C) 2005 Elsevier Ltd. All rights reserved.

Keywords: Small hydropower; Design optimization; Multipurpose NLP optimization; Economical and financial risk analysis

\section{Introduction}

In 1973, with the first petroleum shock, the world economy realized its extraordinary dependence on this fossil fuel.

Consequently, a special attention was focused on improving the use of hydropower resources potential. In the USA a strong impulse was given by the Water and Resources Development Act 1976, which determined the search of the best solutions among a total of 50000 possible sites [14].

Works as $[7,16,17,14]$ can be seen as a result of that effort.

Recently, 16-23 March 2003, the Kyoto Ministerial Conference of the World Water Forum culminated in the ratification of a formal Declaration, which includes specific

\footnotetext{
* Corresponding author. Tel.: + 351 239797149; fax: + 351239797123.

E-mail address: jppgla@dec.uc.pt (J.P.P.G. Lopes de Almeida).
}

0965-9978/\$ - see front matter (C) 2005 Elsevier Ltd. All rights reserved. doi:10.1016/j.advengsoft.2005.06.004 reference to the hydropower important role in sustainable development:

(Item 15) 'We recognize the role of hydropower as one of the renewable and clean energy sources, and that its potential should be realized in an environmentally sustainable and socially equitable manner.'

The need of fulfilling the Kyoto Protocol will press on some public and private investment in hydropower. Yet constraints associated to water use have increased in last decades, due to more demanding environmental legislation and due to increasing water consumption. Consequently multipurpose operation of hydropower plants must be considered.

In some countries small hydropower production can be bought according to sophisticated time-dependent hydroelectric tariff that stimulates production during peaking consumption periods. So production schedule must be optimized to maximize revenue.

These are some of the aspects that make the design of a multipurpose hydropower plant a complex task. The use of optimization techniques in the management and operation of the multipurpose reservoirs of hydropower plants as increased in the past decades. In Yeh [20], Simonovic [15], 
Wurbs [18] and [19], ReVelle [13] and Momoh [10] and [11], an extensive literature review of the optimization techniques and models of complex reservoir systems can be found.

Software models for small hydropower plants analysis have been reported by several institutions as for instance: US Department of Energy; US Bureau of Reclamation; US Army Corps of Engineers; Natural Resources Canada's CANMET Energy Diversification Research Laboratory; IASH International Association for Small Hydro; ESHA European Small Hydropower Association and ADEME Agence pour le Développement et la Maîtrise de l'Énergie. From our point of view, actual available computational facilities and programming techniques allow the development of design models incorporating the increasing complexity of small hydropower projects. In this paper we will describe a design model named OPAH ('Optimisation de Petits Aménagements Hydroélectriques'-Optimization of Small Hydropower Plants), that was developed to consider simultaneously the following aspects:

- the impact of hydrological uncertainty on the optimum project configuration;

- the impact of electric tariff uncertainty on the optimum project configuration;

- the impact of the financial capacity of the investor on the optimum project configuration;

- the impact of the fiscal conditions on the optimum project configuration;

- the impact of the multipurpose operation conditions of the reservoir on the optimum project configuration;

- the impact of the technical characteristics of the turbo-generator units of the power station on the optimum project configuration;

- the impact of the under pressure hydraulic circuit on the optimum project configuration.

\section{Conceptual structure of the OPAH model}

A small hydroelectric power plant (maximum installed power of $10 \mathrm{MW}$ or $30 \mathrm{MW}$ according to each country) can be seen as an industrial investment, subjected to environmental constrains and water use constrains. Actually in most countries this activity is opened to private investors and the production is bought by the national electrical grid according to a tariff. The smaller size of the installations gives more freedom to the design process. Optimum infrastructure size and optimum infrastructure design should provide optimum net present value of the project, taking in to account the hydrologic conditions and hydroelectric tariff during lifetime of the project.

In order to develop the economical and financial analysis of each possible configuration of the hydropower plant, one must know the chronological structure of the expenses and revenues during lifetime of the project. However one cannot know deterministically the future hydrologic conditions and the future hydroelectric tariff. Therefore the OPAH model will consider multiple possible hydrologic and hydroelectric tariff scenarios.

The evaluation of the expenses and revenues demands the previous definition of an infrastructure as well as the operation of this infrastructure during lifetime of the project.

So we conclude that in the optimal configuration search process, one must consider the three main types of problems that must be solved in Water Resources according to Buras [4]:

- the optimal scale of a project;

- the optimal design of its structures;

- the optimal operation of these structures.

Presently the OPAH model applies to hydropower plants composed by the following components:

- earth dam or gravity concrete dam;

- under pressure admission (pipe or tunnel);

- surge tank (if needed);

- penstock;

- power station;

- short canal restitution.

The OPAH model was formulated in order to compute the following decision variables:

- type of dam (earth or concrete gravity dam);

- height of the dam;

- material of the admission conduit;

- diameter of the admission conduit or tunnel;

- shell thickness along the admission conduit;

- material of the penstock;

- diameter of the penstock;

- shell thickness along the penstock;

- diameter of the surge tank;

- vertical length of the surge tank;

- throttling of the surge tank;

- profile of the hydraulic circuit;

- type of turbines;

- number of units;

- rated power of each unit.

The considerable number of issues forced us to adopt an approach based on the division of the global problem in to the five following topics:

- BAR ('BARrage'-Dam);

- CH ('Circuit Hydraulique'-Hydraulic Circuit);

- CEN ('CENtrale'-Power Station);

- BUD (BUDget);

- AEF ('Analyse Économique et Financière'Economical and Financial Analysis). 
For each topic a specific computational module was developed. In the following paragraphs we'll briefly describe these five modules, as well as the links between them. These five modules all together constitute the OPAH model.

\section{Optimal operation of the multipurpose reservoir-the BAR module}

The OPAH model can compare the performance of different configurations of hydropower plants, from run-ofriver hydropower plants to hydropower plants with storage capacity. In the operation of hydropower plants with reservoirs it is imperative to take advantage of the storage capacity, for instance by accumulating water to produce energy mainly in peak consumption periods. The constraints associated to multipurpose operation of hydropower plants makes it impossible to evaluate the maximum annual benefit using the classical approaches based on the Flow Duration Curve or on the Power Duration Curve. Given the diversity of possible infrastructure configurations and possible multipurpose water use constraints, it doesn't seem appropriated to adopt fixed operation rules. In order to evaluate the maximum annual benefit associated to each specific configuration, the BAR module adopted an optimization of the multipurpose reservoir operation. A non-linear formulation, with non-linear objective function and nonlinear constrains, was implemented. The model was solved using non-linear programming NLP.

The non-linear optimization of the multipurpose reservoir operation considered the flowing items:

- flow in to the reservoir;

- precipitation and evaporation in the reservoir;

- obligatory seasonal discharges from the dam to the river bed by-passed by the hydraulic circuit;

- obligatory seasonal discharges down-stream the hydraulic circuit;

- obligatory seasonal extractions from the reservoir to irrigation or water supply;

- maximum and minimum admissible operating head of the turbines;

- maximum and minimum admissible operating flow of the turbines;

- variation of the power station efficiency with the head and flow;

- maximum and minimum admissible seasonal pool levels;

- curve with water level versus flow at the end of the hydraulic circuit;

- time-dependent electric production tariff (energy and power).

In order to incorporate the hydrological variability, several reservoir operation optimizations are done considering five types of hydrological years; a dry hydrological year; a dry/normal hydrological year; a normal hydrological year; a normal/wet hydrological year; and a wet hydrological year.

When site characteristics allow two possible types of dams, earth and concrete gravity dam, the least cost solution is chosen based on cost estimations carried out by the BUD module.

The PREGAMS.EXE is an executable file, included in the BAR module, that accomplishes a previous processing of PILAR.DAT input data file. This executable file also writes the code of the programs that will compute the multipurpose reservoir operation optimization. This code is written in GAMS programming language. A description of GAMS/MINOS software, adopted to solve the optimization problem, can be found in [3].

In Fig. 1 we present a scheme with the constitution of the OPAH model.

In Fig. 2 we present a scheme with the functioning and interconnection of the BAR module files.

In Fig. 3 we present a typical real data graphical output of the BAR module with the evolution of several parameters associated to the optimal operation policy along a wet year.

\section{Analyzing the hydraulic circuit-the $\mathrm{CH}$ module}

The output files of the BAR module provide, to the $\mathrm{CH}$ module, the gross heads and the flows associated to the optimum reservoir operation policy. These values are computed in the 1460 time intervals in witch the year is divided (4 time intervals in each day according to 4 different daily hydroelectric tariff prices). Based on these values the $\mathrm{CH}$ module generates a set of possible configurations of the hydraulic circuit.

The user must define a plan scheme of the hydraulic circuit. He must also define an initial profile of the hydraulic circuit. Other data as for instance: ground and conduit coordinates; ground slope in the orthogonal direction of the conduit; excavation and embankment unitary costs, are written in the TRACE.DAT data file.

The data associated to each configuration of the hydraulic circuit, as for instance: conduits material; bound admissible flow velocities; possible diameters in the admission conduit (or tunnel) and in the penstock; possible diameters and possible entrance throttling of the surge tank, are written in the file CONDUITES.DAT.

The analysis of each possible configuration of the hydraulic circuit (configurations with and without surge tank are always tested) comprises the simulation of the extreme pressure conditions. These extreme pressure conditions are due to user defined opening and closing maneuvers (when an under-pressure tunnel is adopted the user must define the celerity and maximum allowable pressure). An elastic unsteady flow numerical simulation model, based on the resolution of water hammer equations 


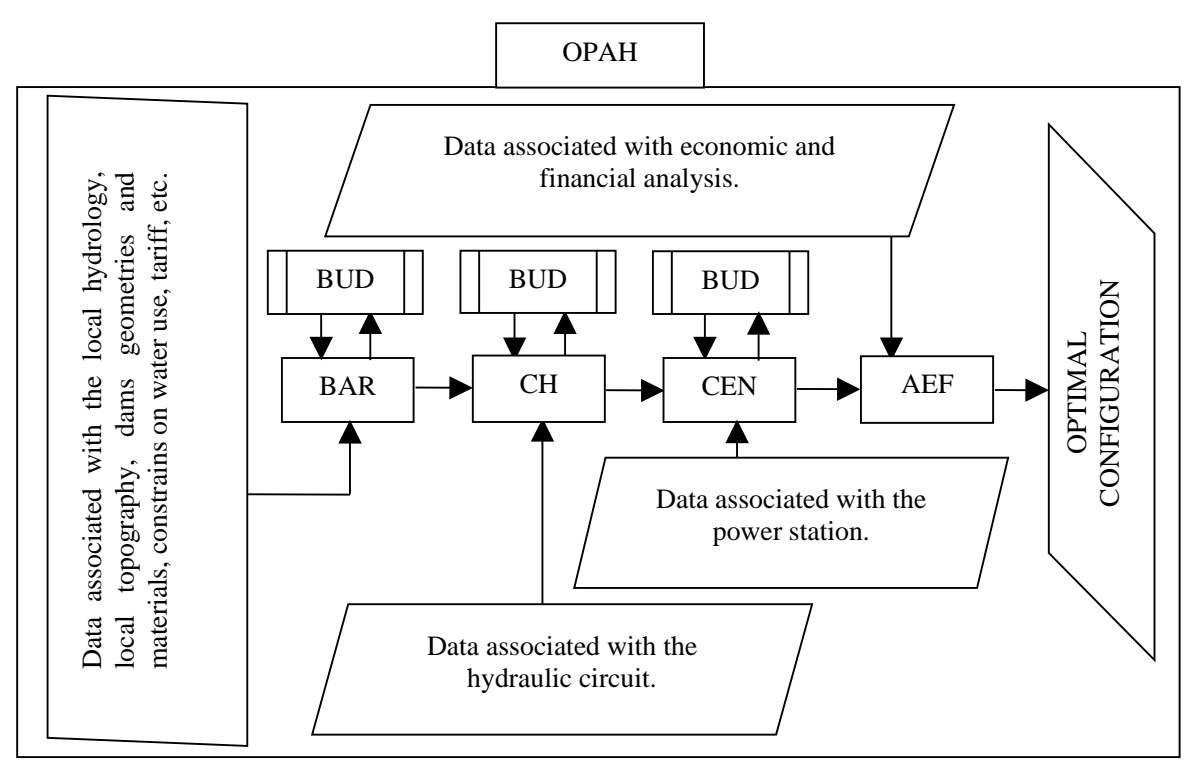

Fig. 1. Schematic constitution of the OPAH model.

by the Characteristics Method, due to Marques [9], was adapted and incorporated in the $\mathrm{CH}$ module.

The evaluation of maximum pressure conditions is necessary to compute the thickness of the conduits (or to check if maximum allowable pressure in the under-pressure tunnel is not exceeded).

The evaluation of minimum pressure conditions is necessary to check if cavitation occurs. If cavitation occurs the initial profile of the hydraulic circuit is lowered at the critical points (witch will increase the associated excavation costs).

The BUD module computes the cost of the feasible configurations of the hydraulic circuit.

Given a certain diameter and material of the admission conduit (or the diameter of the under-pressure tunnel and maximum allowable pressure) and given a certain diameter and material of the penstock, an enumerative search is done in order to identify the configuration leading to the minimum total cost of the hydraulic circuit. This configuration will be characterized by the hydraulic circuit profile, thickness of the conduits and by the surge tank characteristics (if a surge tank is advantageous).

The $\mathrm{CH}$ module evaluates the reduction of the initial revenue estimative, computed by the BAR module, taking into account the head losses in each configuration of the hydraulic circuit and taking into account the time-dependent hydroelectric tariff.

In Fig. 4 we present a scheme with the constitution, function and interconnection of the $\mathrm{CH}$ module files.

\section{Analyzing the power station-the CEN module}

Each unit of the power station presents is own efficiency curve that varies with the type of turbine, flow and net head.
Each unit is also characterized by specific bounds of operating heads and operating flows.

Given a certain rated power, the power station can be equipped with a single unit or the total rated power may be divided by multiple (equal or unequal) units.

When multiple units are adopted, one can accomplish a judicious distribution of total flow through the operating units in order to achieve global maximum efficiency of the power station. Another advantage is the possibility of enlarging the operating flow bounds by reducing the minimum operating flow. In order to consider these aspects the CEN module adopted a standardization of the distribution of total rated power by the units. The CEN module computes the global optimum electrical power output curve of each of these standardized power station configurations. The optimization process uses digitalized adimensional curves that provide the adimensional values of the electrical power output of a single unit as a function of the adimensional values of flow and head. These values are made adimensional by dividing them by the corresponding rated values. This type of curves can be found in [7]. For each standardized power station configuration, several possible adimensional operating heads are considered. For each adimensional operating head, all feasible partitions of adimensional total flow by the units are considered. After, an enumerative search process is accomplished in order to identify and store the partitions leading to maximum power output. This optimization process is done by the executable file OPTUR.EXE before the first run of the OPAH model. Optimum electrical power output curves of each standardized power stations are stored in data file GLOBTUR.DAT. This data will be consulted several times in future by the CEN module.

In the data file CENTRALE.DAT the user defines the characteristics associated to the power station as for 
PILAR.DAT

(input file: incoming flow; rain fall; evaporation; water use constrains; hydroelectric tariffs; topography;

dam geometry; stored water curve; computational steps for dam height search and rated power search;

cost data associated to dam and terrain; data about solid flow transport; time for reservoir emptying:

curve with water level versus flow at the end of the hydraulic circuit)

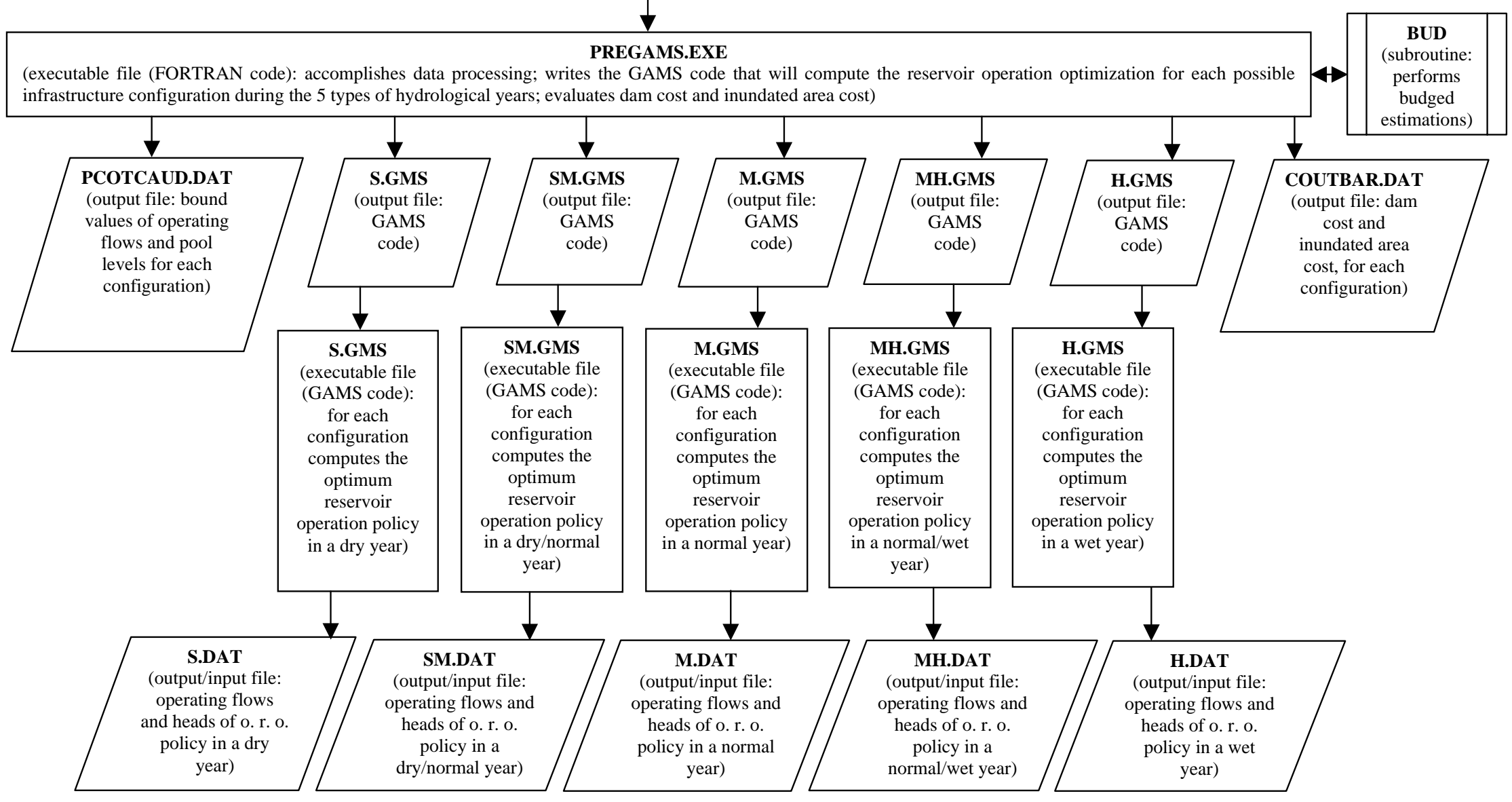

Fig. 2. Schematic constitution of the BAR module. 

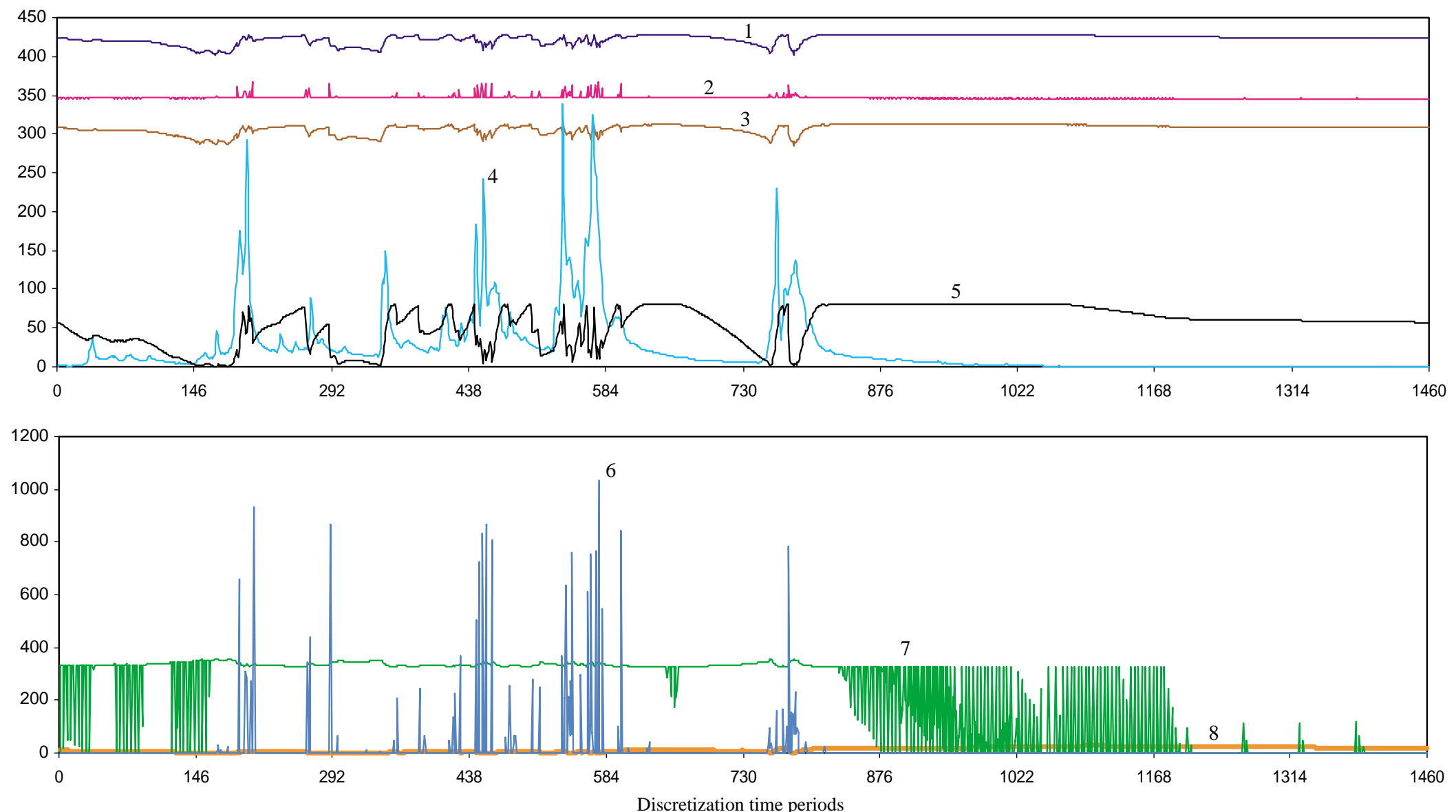

1-Water level in the reservoir $(\mathrm{m}) ; 2$-Water level at the end of the hydraulic circuit $\left(3^{-1} \mathrm{~m}\right) ; 3$-Gross head $(\mathrm{m}) ; 4$-Inflow $\left(5^{-1} \mathrm{~m}^{3} \mathrm{~s}^{-1}\right) ; 5$-Stored water in the reservoir $\left(5^{*} 10^{4} \mathrm{~m}^{3}\right) ; 6$-Non turbined outflow $\left(5^{-1} \mathrm{~m}^{3} \mathrm{~s}^{-1}\right) ;$ 7-Turbined outflow $\left(10^{-2} \mathrm{~m}^{3} \mathrm{~s}^{-1}\right) ; 8$-Evaporated flow $\left(10^{-3} \mathrm{~m}^{3} \mathrm{~s}^{-1}\right)$

Fig. 3. Typical plot of an optimum operation policy along a wet year computed by the BAR module. 


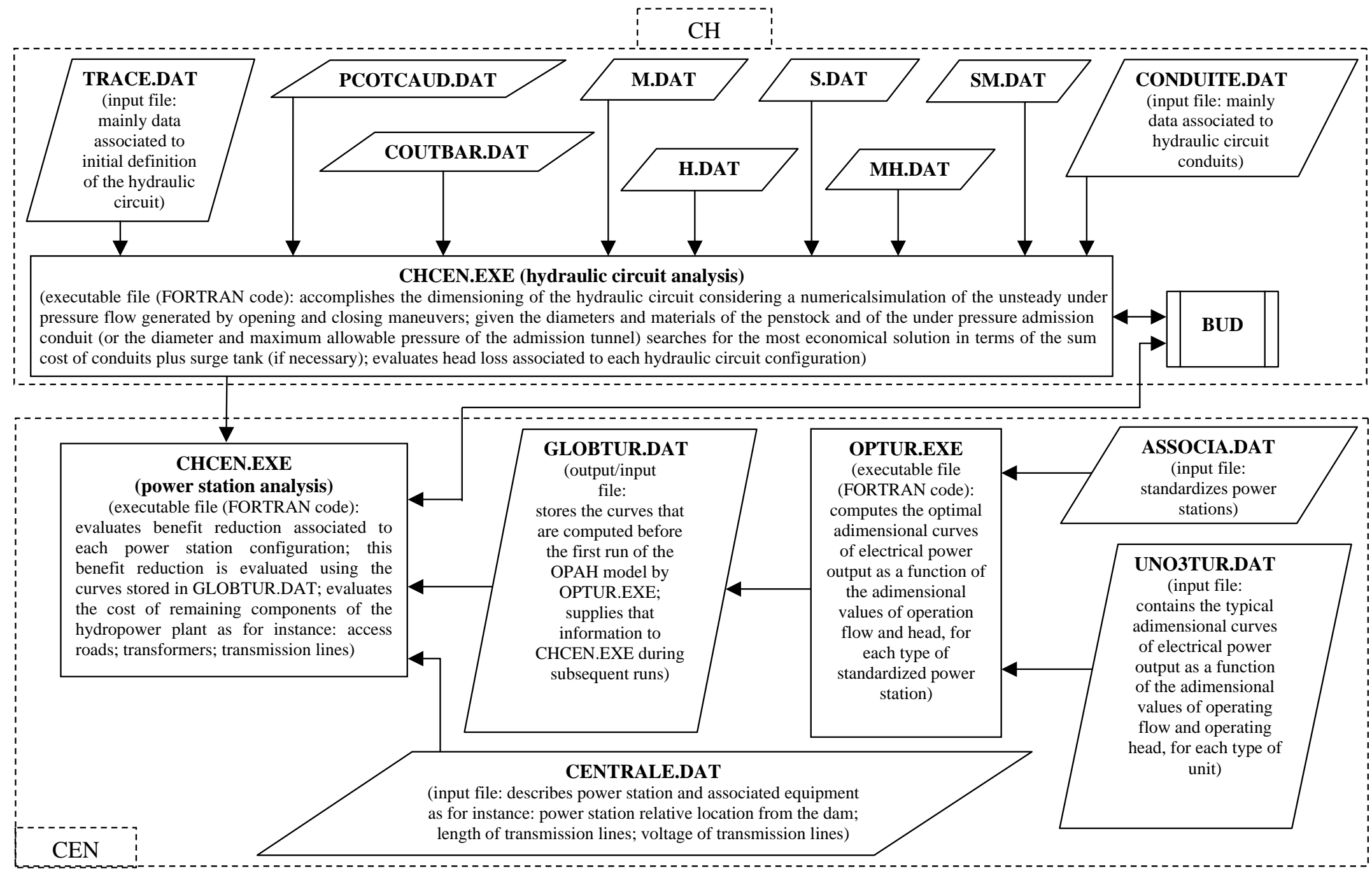

Fig. 4. Schematic constitution of the $\mathrm{CH}$ and CEN modules. 

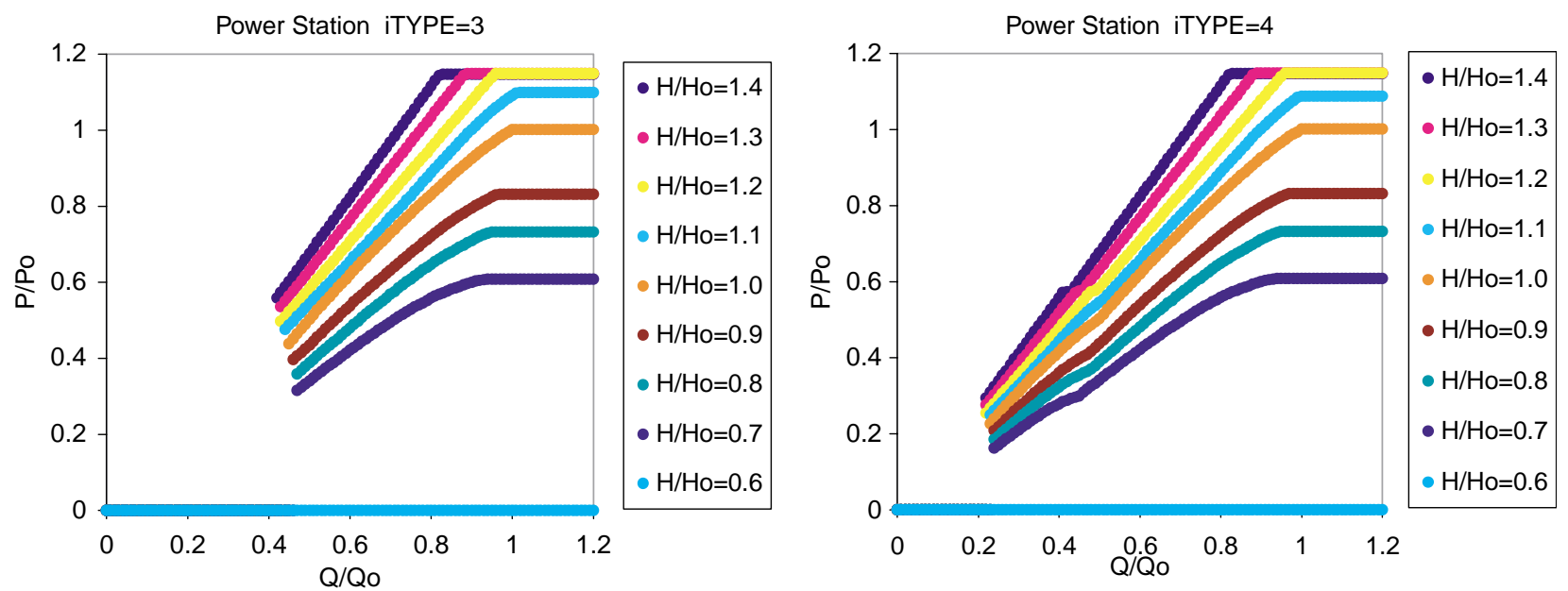

Fig. 5. Typical optimum efficiency curves for two different configurations of the power station (one and two Kaplan units).

instance: the power station positioning; the transmission lines voltage; the transmission lines length; the transmission lines foundation type.

The analysis developed by the $\mathrm{CH}$ and CEN modules, was implemented in the executable file CHCEN.EXE.

Due to limitations of operating flows and power station efficiency, the revenue estimative supplied by the $\mathrm{CH}$ module must be reduced. For each possible rated output power, the CEN module evaluates the revenue reduction associated to each possible power station configuration.
The cost of each possible power station configuration is computed by the BUD module.

In Fig. 4 we present a scheme with the constitution, function and interconnection of the files involved in the CEN module.

In Fig. 5 we present typical real data optimum efficiency curves for two different configurations of the power station, computed by the CEN module.

In Fig. 6 we present a typical real data output plot obtained after running the $\mathrm{CH}$ and the CEN modules.

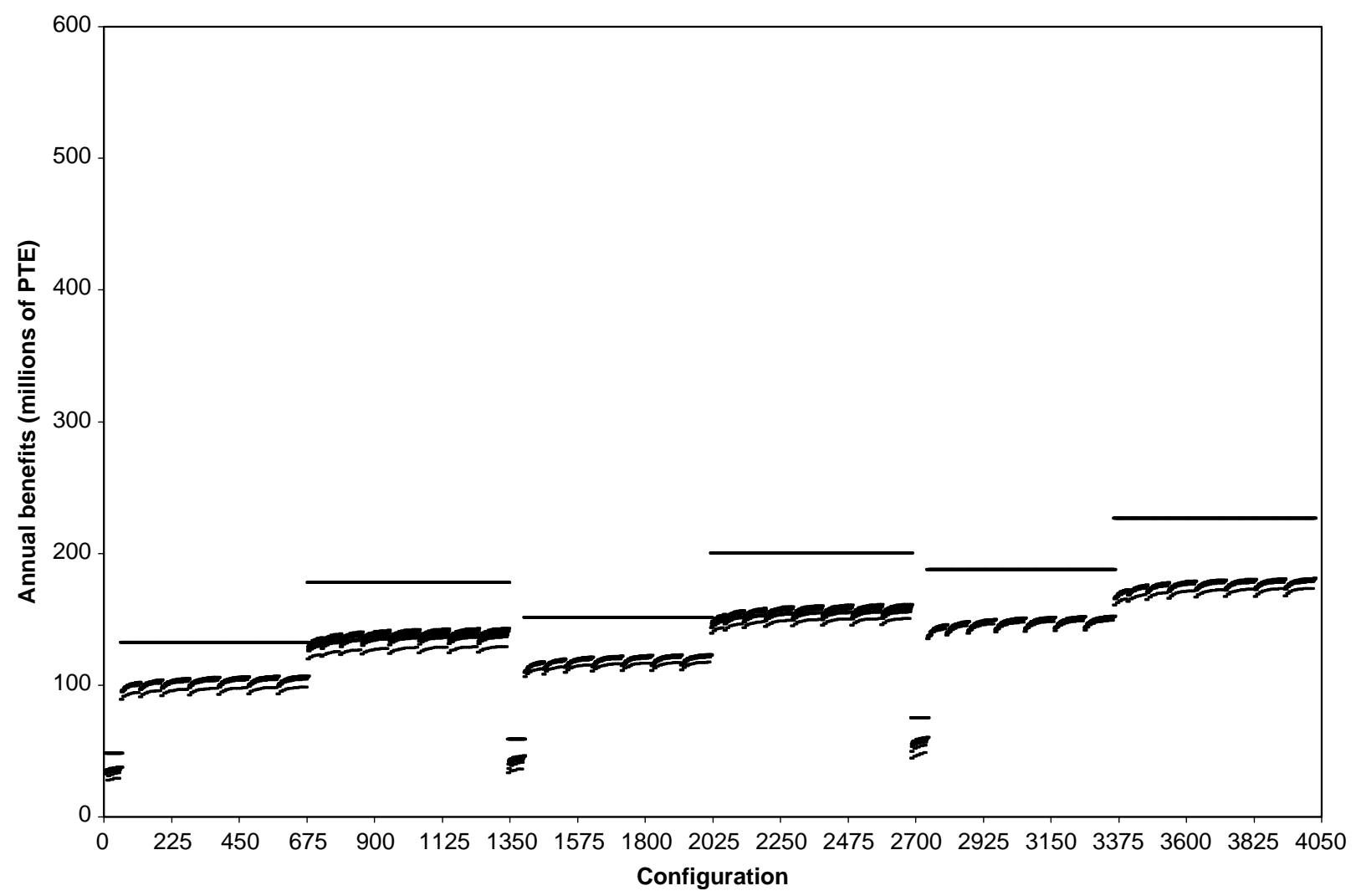

Fig. 6. Comparison between annual benefits during a dry hydrological year for 4021 possible configurations of a small hydropower plant: computed by the BAR module (strait lines); computed after cumulative action of the $\mathrm{CH}$ and CEN modules (dot points). 


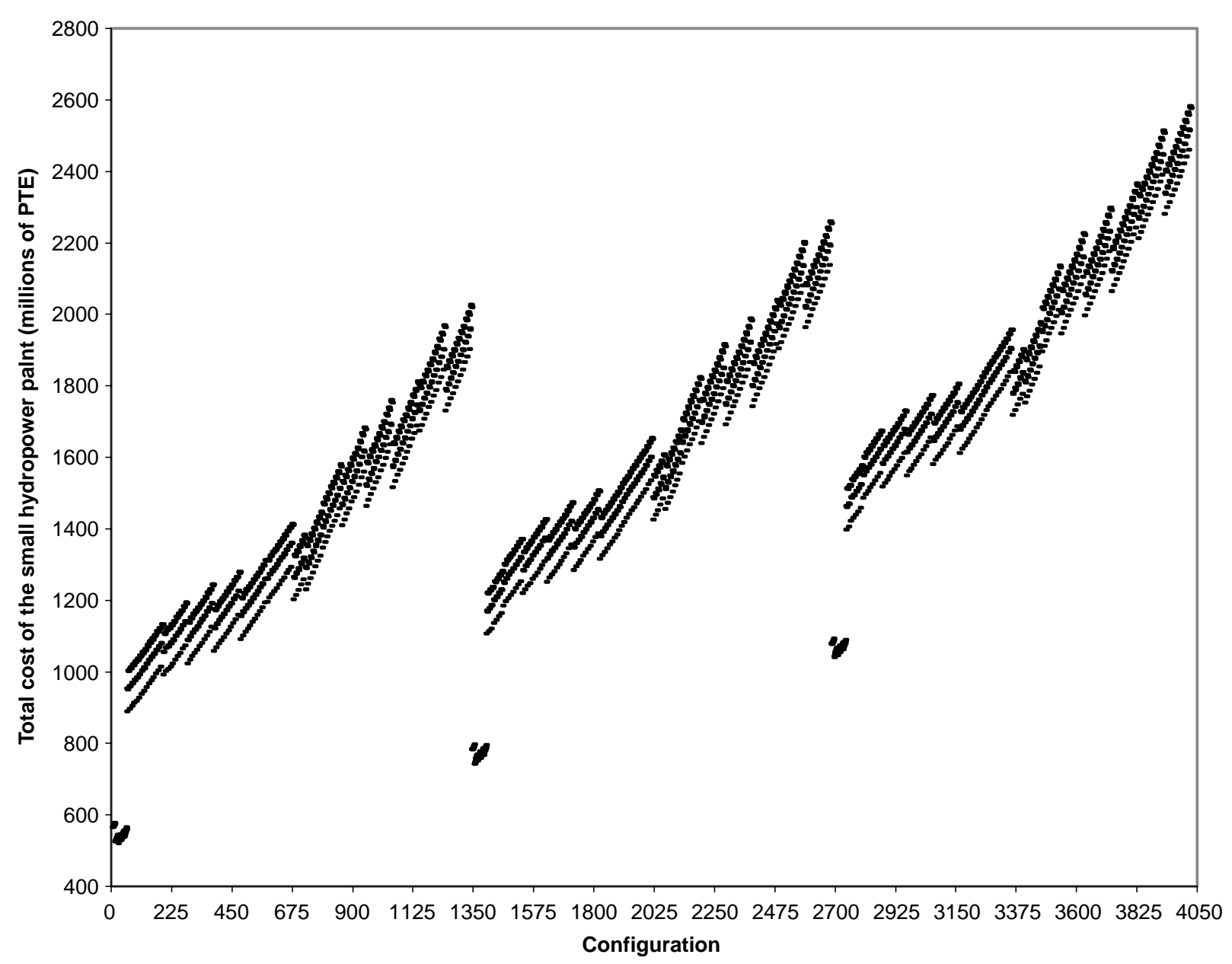

Fig. 7. Typical output of the BUD module with the total estimated cost of 4021 possible configurations of a small hydropower plant.

For each configuration of the hydropower plant we can see the theoretical optimum annual benefit, initially computed by the BAR module, and the real annual benefit computed after the cumulative action of the $\mathrm{CH}$ and the $\mathrm{CEN}$ modules.

\section{Estimating the cost of each configuration-the BUD module}

After the global design of the main elements of the hydropower plant, cost estimations can be developed.

The present version of the BUD module adopts an estimating cost process based on several cost functions obtained from international specialized bibliography as for instance: $[7,16,17,14,5,6,8]$.

The costs were updated using cost index historical data. Exchange corrections were also considered.

The modular character of the OPAH model allows the adoption of other BUD modules, based in different cost data contexts.

The interconnection of the BUD module with the other modules of the OPAH model is schematically presented in Figs. 2 and 4.
In Fig. 7 we present a typical real data output plot of the BUD module with the total estimated cost of 4021 possible configurations of a small hydropower plant.

\section{Economical and financial analysis—-the AEF module}

The CEN module supplies to the AEF module a set of dimensioned configurations of the hydropower plant. For each of these configurations we know the construction cost. We also know the annual revenue (computed taking into account the cumulative influence of the reservoir, hydraulic circuit and power station) in each of the five types of hydrological years (this information is written by the CEN module in the AEFDAD.DAT data file).

As mentioned in item 3, the operation of the hydropower plant was guided by a multipurpose reservoir operation optimization, in order to fully evaluate the specific advantages of each configuration. However, in practical terms, the real operation of the hydropower plant will never achieve the optimal values. To account for this aspect, the AEF module allows the definition of a diminishing 


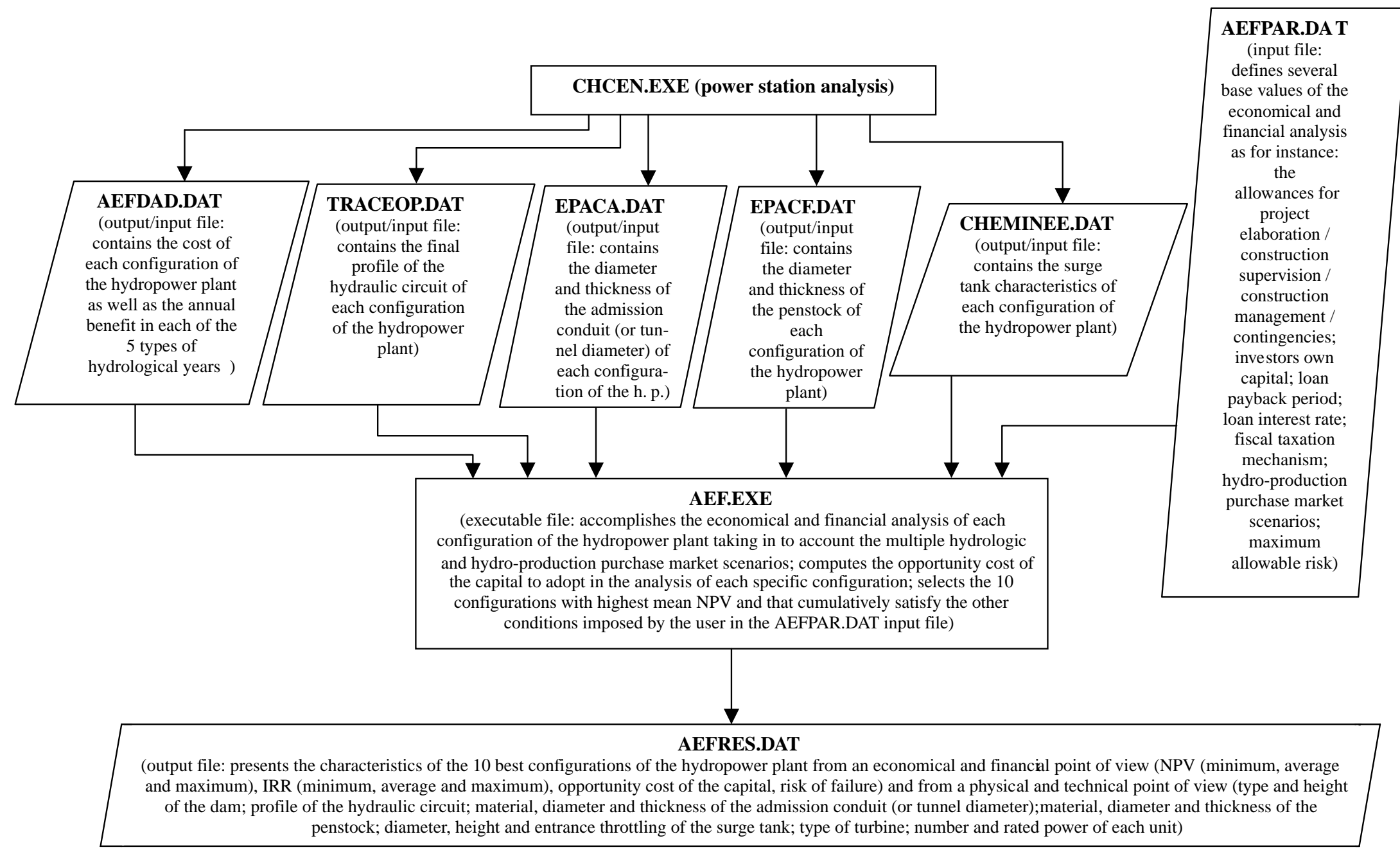

Fig. 8. Schematic representation of CEN results and AEF module. 


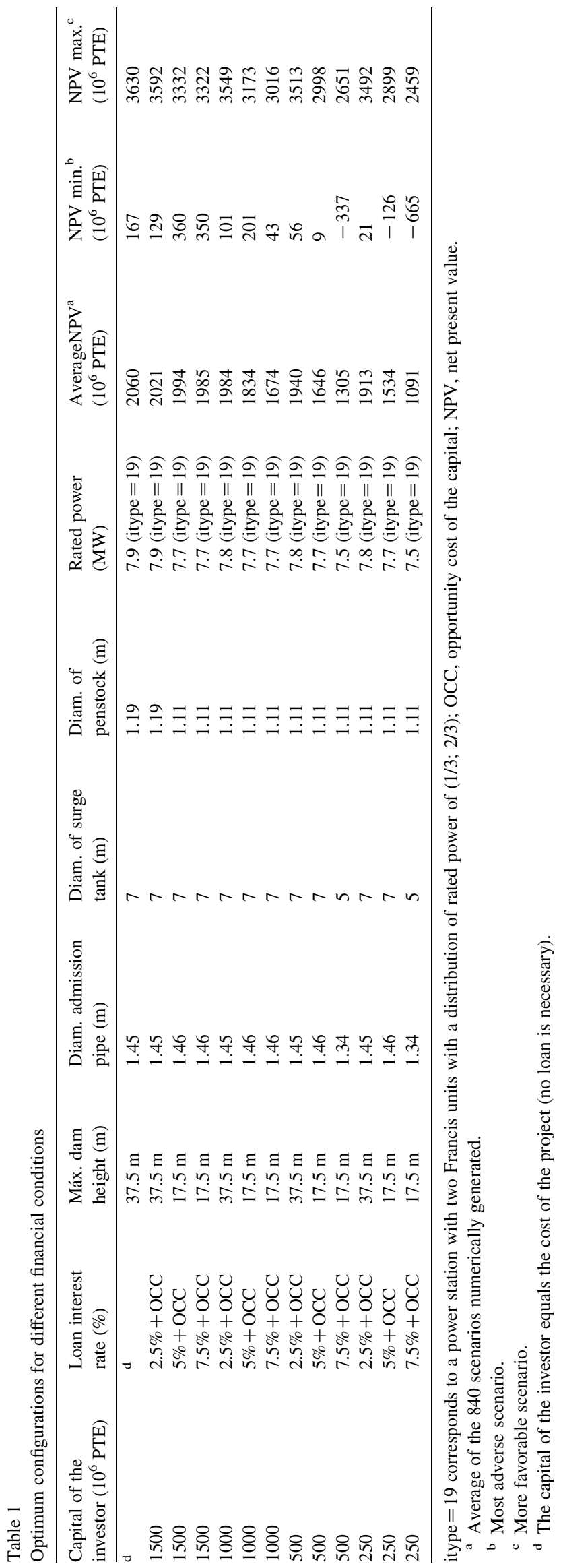

coefficient, in order to use more prudential estimates of annual revenue.

The physical and technical characteristics of all the dimensioned configurations of the hydropower plant are stored in the TRACEOP.DAT, EPACA.DAT, EPACF. DAT and CHEMINEE.DAT data files. At the end of the process, the AEF module will consult these backup files to recover detailed information about the final optimal configurations.

The economical parameter adopted to measure the economical merit of each configuration was the NPV (Net Present Value). A detailed exposition of the reasons that recommend the adoption of this economic parameter can be found in [2].

In order to determine the NPV one must know the chronological structure of project revenues and expenses, during lifetime of the project. The expenses must comprise financial expenses as well as fiscal expenses.

The evaluation of financial expenses is done after knowing the investor's available capital and the loan interest rate. The loan interest rate can be indexed to the project risk or can be imposed by the user.

The evaluation of the fiscal expenses demands the definition of the legal fiscal taxation mechanism, specific of each country.

The user defines all these values in the AEFPAR.DAT data file.

In order to determine the NPV one must adopt a discount rate that reflects the opportunity cost of capital of the project. The AEF module evaluates the opportunity cost of capital of each configuration, based on a previous estimate of the bankruptcy risk of the project. In order to evaluate the bankruptcy risk of the project, a simulation approach is considered. In this simulation several hydrological scenarios and several hydroelectric tariff scenarios, during lifetime of the project, are considered. The hydrological scenarios generation is always based on the initially defined five types of hydrological years. The hydroelectrical tariff scenarios are arbitrated by the user in the AEFPAR.DAT data file.

After bankruptcy risk evaluation, the discount rate is computed using a standard relation between bankruptcy risk and mean annual profitability. This relation was obtained from a historical analysis of the USA financial market. However from AEFPAR.DAT data file the user is free to define any other relation.

After accomplishing the economical and financial analysis of all the feasible configurations of the hydropower plant, the AEF module identifies the 10 configurations that present maximum mean NPV and that cumulatively satisfy other parameters imposed by the user (as for instance maximum allowable bankruptcy risk). From backup data files consultation, the AEF module recovers the physical and technical detailed characteristics of the 10 best configurations, witch are presented to the user in AEFRES.DAT results data file. 
In Fig. 8 we schematically present the constitution, function and interconnection of the files involved in the CEN and AEF modules.

\section{Conclusions}

The OPAH model was successfully applied to the reanalysis of an already constructed hydropower plant: the small hydropower plant of Catapereiro, in the Teja river of Portugal, UE. This hydropower plant is characterized by a concrete gravity dam with $37.5 \mathrm{~m}$ maximum height above foundation, by a metallic admission conduit with a length of $7050 \mathrm{~m}$ and a diameter of $1.45 \mathrm{~m}$, by a metallic penstock with a length of $890 \mathrm{~m}$ and a diameter of $1.10 \mathrm{~m}$, by a gross head of $315 \mathrm{~m}$ and by a rated power of $8 \mathrm{MW}$, as presented in [12]. In this example we adopted the original currency: PTE-Portuguese escudos.

When only an economical approach was considered, we found that the real project configuration was close to the optimal configuration provided by the OPAH model.

However when the financial and fiscal aspects were cumulatively considered, we found that the optimum configuration computed by the OPAH model could diverge from the real project configuration, particularly on what concerns dam height. This showed the significant impact of the financial and fiscal aspects. In Table 1 we present a typical output of the OPAH model. We can see that the main characteristics of the optimum configurations of the small hydropower plant are influenced by the financial conditions of the investor.

A detailed description of the mathematical, physical and economical bases of the OPAH model, as well as results of its application, is beyond the scope of the present paper. This description can be found in [1].

\section{References}

[1] Almeida JP. Développement d'un modèle global pour l'optimisation économique et financière de la configuration de petits aménagements hydroélectriques à buts multiples avec circuit hydraulique en pression, Ph.D. dissertation. Liège: Université de Liège; 2000.
[2] Brealey RA, Myers SC. Princípios de finanças empresariais. 3rd ed. Portugal: McGraw-Hill; 1992.

[3] Brooke A, Kendrick D, Meeraus A. GAMS a user's guide. South San Francisco: The Scientific Press; 1992.

[4] Buras N. Scientific allocation of water resources American. New York: Elsevier Publishing Company; 1972.

[5] Castelli B, Hartmann O, Ravicini L. Cost and economics of hydroplant modernisation. Water Power Dam Construct 1993; (December).

[6] Goldsmith K. Economic and financial analysis of hydropower projects, hydropower development. Norway: Norwegian Institute of Technology Division of Hydraulic Engineering; 1993.

[7] Hydrologic Engineering Center. Institute for water resources Feasibility studies for small scale hydropower additions: a guide manual. USA: U S Army Corps of Engineers; 1979.

[8] Lencastre A, Piedade J. Instrumentos de apoio a uma política de desenvolvimento sustentável em saneamento básico: custos de construção e exploração. Lisboa: Direcção Geral do Ambiente; 1994.

[9] Marques J. Contribution à l'étude numérique et expérimentale des systèmes des aménagements hydroélectriques avec deux chambres d'équilibre et à la stabilité du réglage des groupes, Ph.D. dissertation. Liège: Université de Liège; 1987.

[10] Momoh JA, El-Hawary ME, Adapa R. A review of selected optimal power flow literature to 1993, part I: nonlinear and quadratic programming approaches. IEEE Trans Syst 1999;14(1):96-104.

[11] Momoh JA, El-Hawary ME, Adapa R. A review of selected optimal power flow literature to 1993, part II: newton, linear programming and interior point methods. IEEE Trans Syst 1999;14(1):105-11.

[12] PEEC Planos e Estudos de Eng. Civil Lda. Aproveitamento Mini Hídrico do Catapereiro, Project. Portugal: Câmara Municipal de Vila Nova de Foz Côa; 1992.

[13] ReVelle C. Water resources: surface water systems, chapter 1 Design and operation of civil and environmental engineering systems. New York: C ReVelle and AE McGarity eds Wiley; 1997 p. 1-39.

[14] Sant'Ana RF. Assessing the feasibility of small hydroelectric power plants, Ph.D. dissertation. USA: Colorado State University; 1983.

[15] Simonovic SP. Reservoir systems analysis: Closing gap between theory and practice. J Water Resour Plan Manage 1992;118(3): $262-80$.

[16] Tudor Engineering Company. Reconnaissance evaluation of small low-head hydroelectric installations Report. USA: Water and Power Resources Service; 1980.

[17] Tudor Engineering Company. Simplified Methodology for economic screening of potential low-head small-scale hydroelectric sites Report. USA: Electric Power Research Institute; 1981.

[18] Wurbs RA. Reservoir-system simulation and optimization models. J Water Resour Plan Manage 1993;119(4):455-72.

[19] Wurbs RA. Modeling and analysis of reservoir system operations. NJ: Prentice Hall; 1996.

[20] Yeh WW-G. Reservoir management and operation models: a state-ofthe art review. Water Resour Res 1985;21(12):1797-818. 